\title{
Diagnostic Rigid Urethrocystoscopy: Indications, Results and Pain Assessment
}

\author{
Ousmane Sow ${ }^{1}$, Abdoulaye Ndiath ${ }^{1}$, Aboubacar Traore ${ }^{2}$, Alioune Sarr ${ }^{1}$, Babacar Sine ${ }^{1}$, \\ Modou Ndiaye1, Yassin Sayerh'1, Cyrille Ze Ondo', Amath Thiam1', Ndiaga Seck Ndour1, \\ El Hadj Malick Daw', Ndeye Aissatou Bagayogo', Yaya Sow ${ }^{1}$, Boubacar Fall'2, \\ Babacar Diao', Papa Ahmed Fall ${ }^{3}$, Alain Khassim Ndoye ${ }^{1}$
}

${ }^{1}$ Urology-Andrology Department, Aristide Le Dantec Hospital, Dakar, Senegal

${ }^{2}$ Urology-Andrology Department, De la Paix Hospital, Ziguinchor, Senegal

${ }^{3}$ Urology-Andrology Department, Dalal Jamm Hospital, Dakar, Senegal

Email: *sowman87@yahoo.fr

How to cite this paper: Sow, O., Ndiath, A., Traore, A., Sarr, A., Sine, B., Ndiaye, M., Sayerh, Y., Ze Ondo, C., Thiam, A., Ndour, N.S., Daw, E.H.M., Bagayogo, N.A., Sow, Y., Fall, B., Diao, B., Fall, P.A. and Ndoye, A.K. (2020) Diagnostic Rigid Urethrocystoscopy: Indications, Results and Pain Assessment. Open Journal of Urology, 10, 239-244.

https://doi.org/10.4236/oju.2020.108028

Received: August 5, 2020

Accepted: August 24, 2020

Published: August 27, 2020

Copyright $\odot 2020$ by author(s) and Scientific Research Publishing Inc. This work is licensed under the Creative Commons Attribution International License (CC BY 4.0).

http://creativecommons.org/licenses/by/4.0/

(c) (i) Open Access

\begin{abstract}
Background: Over the last 50 years, endourology has revolutionized urological practices worldwide. This is not so in many urological centers in West Africa. Although, some centers have made progress in the level of urological services that they offer; many of such centers provide rigid urethrocystoscopy services. Rigid urethrocystoscopy is an endoscopic examination that explores the urethra, bladder and prostate in men. Aims: We report the indications, results and pain assessment of rigid urethrocystoscopy in our center. Patients and Methods: We carried out a retrospective, descriptive, monocentric study in our center between January 2016 and June 2018. The study included all patients who had a rigid urethrocystoscopy under local anaesthesia. We studied the following parameters: sex, age, indications for the examination, outcomes and the pain assessment. Results: Five hundred and forty-one patients were included. The sex-ratio was 1.49. The mean age was $49.47 \pm 18.48$ years (12 years and 91 years). Lower urinary tract symptoms (29\%) and hematuria (28\%) were the most common indications. The rigid urethrocystoscopy was normal in $26.8 \%$ of patients. Bladder tumors $(21.2 \%)$ were the most frequent lesions. In men, prostate tumors were more common (21\%) followed by bladder tumors $(17.9 \%)$, while in women, bladder tumors $(26.3 \%)$ were predominant followed by cystopathy lesions (12.4\%).The mean Simple Verbal Scale (SVS) score was 1.25 in women and 2.1 in men. Conclusion: Rigid urethrocystoscopy was relatively well tolerated by our patients. Hematuria was the primary indication and the main etiologies were bladder and prostate tumors.
\end{abstract}


Keywords

Rigid Urethrocystoscopy, Bladder Tumors, Hematuria

\section{Introduction}

Urethrocystoscopy is an endocavitary exploration under visual control of the lower urinary tract. It is a common practice examination in urology that has undergone numerous modifications to date, allowing better results and greater comfort for the practitioner and the patient [1]. It is increasingly performed on an outpatient basis under local anesthesia. Despite the existence of other lower urinary tract diagnostic methods, urethrocystoscopy is an important diagnostic tool in a wide range of diseases dominated by bladder tumors often revealed by hematuria [2]. The practice of endourology remains limited in our context, contrary to the Western where it is commonly used [3]. In Senegal, Jalloh et al. [4] reported that hematuria was the main indication for urethrocystoscopy and the etiologic diagnosis was dominated by bladder and prostate tumors. The aim of our study was to determine the profile of patients who underwent a diagnostic rigid urethrocystoscopy and to describe the indications, results and pain assessment.

\section{Patients and Methods}

This is a retrospective, descriptive, single center study conducted in our department between January 2016 and June 2018. The data were collected from records archived in the department during the study period. All patients who underwent rigid urethrocystoscopy (RU) under local anaesthesia and whose records were archived were included. Ten $\mathrm{ml}$ of $2 \%$ lidocaine gel, administered through the external urethral orifice, was used for local anaesthesia in men. The material used was:

- Optics $12^{\circ}$ and $30^{\circ}$.

- A sheath 22 Fr.

- Cold light.

- The camera and monitor.

Urine culture was not systematically done before the urethrocystoscopy.

Studied parameters were: sex, age, indications, outcomes and the pain assessment. Pain tolerance was assessed by phone 24 hours after the exam using a simple verbal scale (SVS):

- No pain: 0 .

- Mild pain: 1 .

- Moderate pain: 2.

- Intense (severe) pain: 3 .

- Extremely intense pain: 4 .

Data collection and analysis were done with Excel 2007 Software. 
We performed descriptive analysis.

\section{Results}

We identified 541 cases over a period of 2.5 years (18 cases per month). The sex-ratio was 1.49 . The mean age was $49.47 \pm 18.48$ years (12 - 91 years). The most frequent indications were lower urinary tract symptoms (29\%) and hematuria (28\%). In men, the most frequent indications were lower urinary tract symptoms (38\%) and hematuria (34\%). In women, the most frequent indication was the assessment for extension of a cervical tumor (40.5\%), followed by hematuria (18.5\%) and lower urinary tract symptoms (16\%) (Figure 1). Urethrocystoscopy was normal in $26.8 \%$ of patients. Bladder tumors (21.2\%) were the most common lesions. In men, prostate tumors were more common (21\%) followed by bladder tumors (17.9\%). In women, bladder tumors (26.2\%) were predominant, followed by cystopathy lesions (12.4\%). Urethral strictures were objectified in 36 men (11.1\%). Urethral stricture was more often localized to the anterior urethra in 32 men (88.9\%), while 9 women (4.2\%) had urethral meatus stricture (Table 1). We performed urethral dilatation in 23 patients $(4.2 \%)$ for a urethral stricture that was objectified at the RU, and 14 patients (2.6\%) had a

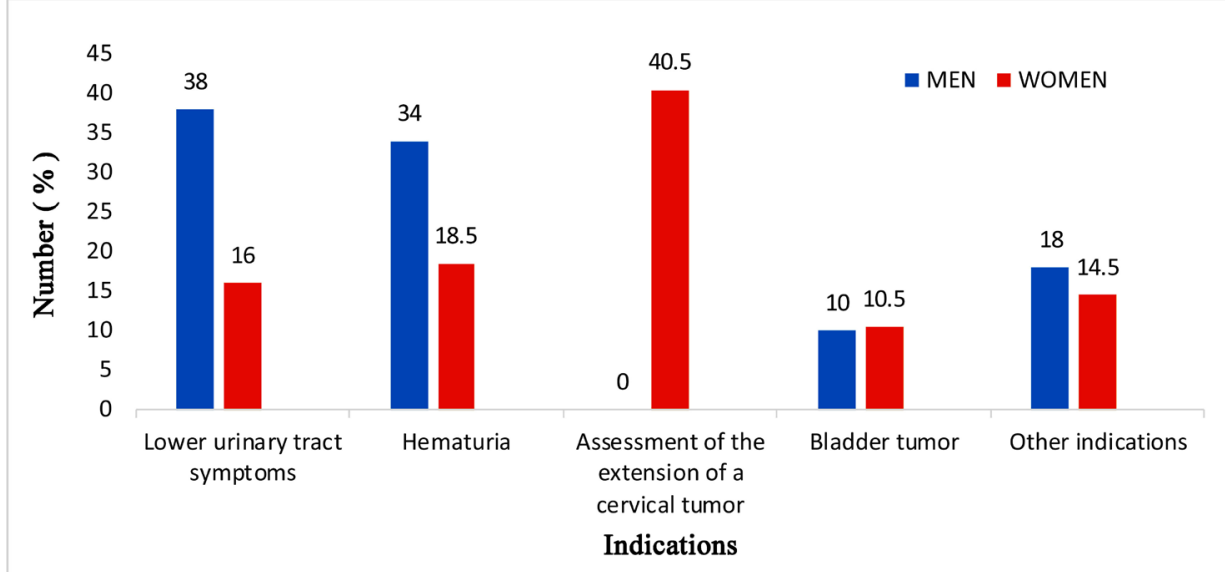

Figure 1. Distribution of indications for rigid urethrocystoscopy according to sex.

Table 1. Types of diseases according to sex.

\begin{tabular}{cccc}
\hline Diseases & Males & Females & Total \\
\hline Bladder tumors & $58(17.9 \%)$ & $57(26.2 \%)$ & $115(21.2 \%)$ \\
Prostate Tumors & $68(21 \%)$ & $0(0.0 \%)$ & $68(12.6 \%)$ \\
Schistosomiasis lesions & $53(16.4 \%)$ & $18(8.3 \%)$ & $71(13.2 \%)$ \\
Cystopathy lesions & $18(5.5 \%)$ & $27(12.4 \%)$ & $45(8.3 \%)$ \\
Urethral Stenosis & $36(11.1 \%)$ & $9(4.2 \%)$ & $45(8.3 \%)$ \\
Other lesions & $32(9.9 \%)$ & $20(9.3 \%)$ & $52(9.6 \%)$ \\
Normal cystoscopy & $59(18.2 \%)$ & $86(39.6 \%)$ & $145(26.8 \%)$ \\
Total & $324(100 \%)$ & $217(100 \%)$ & $541(100 \%)$ \\
\hline
\end{tabular}




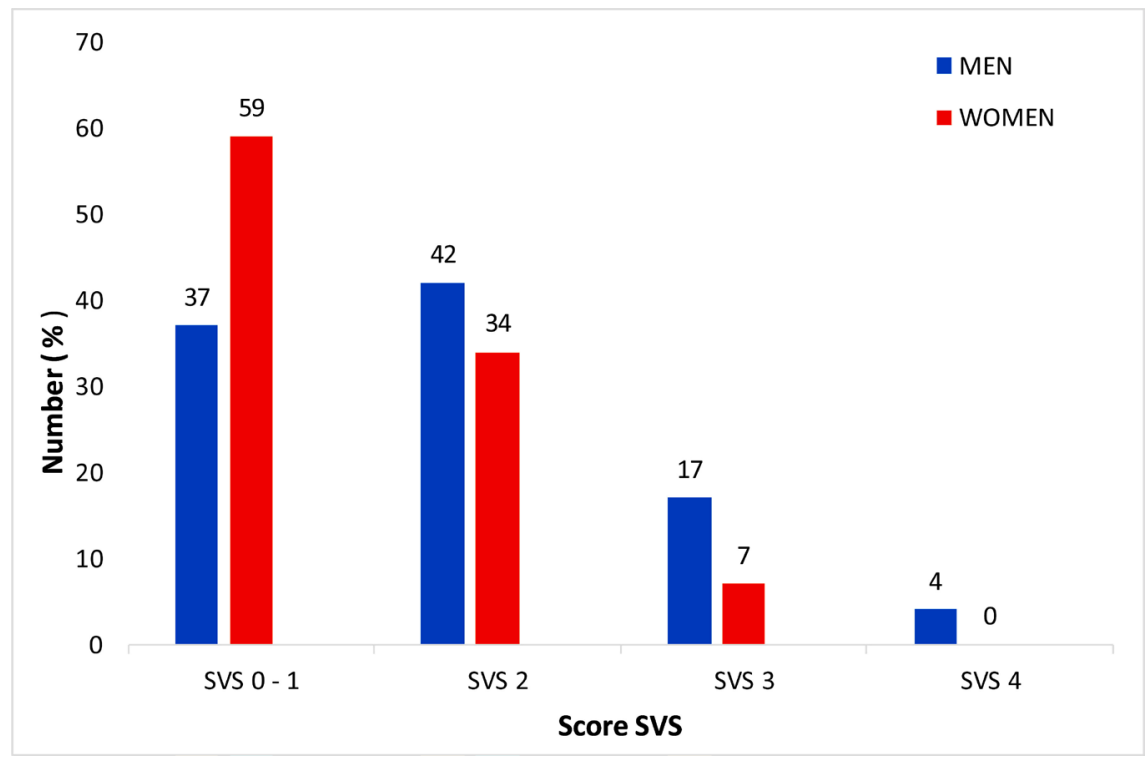

Figure 2. Distribution of patients, according to the simple verbal scale and sex $(n=163)$.

bladder biopsy indicated for a bladder tumor. SVS was assessed in 163 (95 males and 68 females) who accepted the survey. The mean of the SVS was 1.25 in women and 2.1 in men. Pain was higher in men (63\%) than in women (41\%) (Figure 2).

\section{Discussion}

The mean number of RU (18 per month) in our institution was higher than Jalloh's one (13 per month) in similar study in the urology department of Idrissa Pouye Hospital (Dakar, Senegal) [4]. This difference can be explained by the lower cost of the RU in our center but also by the proximity of the RU to the Nephrology, pediatrics and cancer departments. The latter address to us their patients mainly in the cervical tumor extension assessment with particular interest in the state of the ureteral meatus. There is a predominance of males in RU [4] [5]. According to Samuel, hematuria is a risk factor for undergoing cystoscopy [5]. In our study, hematuria was the second indication of RU in men (34\%) and bladder tumors were the most common lesion in our study (21.25\%). The high rate of bladder tumors in our study may be explained by the persistence of bilharzia endemia, which is a risk factor of bladder tumors [6] [7]. Among patients with prostatic tumors, the most frequent indication for examination was lower urinary tract symptoms (29\%), followed by hematuria (28\%). These results are similar to those of Jalloh and al. [4]. Hematuria is a diagnosis of elimination in benign prostatic hyperplasia, and requires more investigation before linking it to benign prostatic hyperplasia [8]. There is a correlation between prostate volume and the risk of hematuria which increase with prostate volume [8]. In our study, 9 women had urethral meatus stricture versus 5 patients in Lee et al. study [9]. Urethral meatus stricture in women is rare. It was commonly caused by traumatic and iatrogenic injuries, or inflammatory disease. Diagnosis 
of urethral meatus stricture in women is clinical. A good clinical examination would have spared 9 of our patients from invasive examination. In our series, women tolerated pain better. This may be explained by the short length of female urethra [10]. Our results are similar to those reported by Goldfischer et al. [11] who noted a higher mean level of pain perception in men during RU. However, this painful perception during RU could be decreased by using flexible cystoscopy in our center. Flexible cystoscopy considerably reduce pain compared to rigid cystoscopy [12] [13] [14]. Urine culture was not systematic before urethrocystoscopy and any antibioprophylaxy is needed before endourological procedure without tissue invasion, except in the case of abnormal urinary tract [15] [16]. Thus, in our country, due to financial cost of urine culture and long waiting period before results, we often dispensed with this examination before RU. The limits of our study were certainly the lack of data in children. RU is performed under general anaesthesia in children. We only included patients who had local anaesthesia. Due to the retrospective study nature of our study, we excluded some patients because of missing data.

\section{Conclusion}

Rigid urethrocystoscopy is a useful technique for diagnosis in low urinary tract diseases. Bladder and prostate tumors were the more common diseases objectified. Hematuria and lower urinary tract symptoms were the most frequent indications for urethrocystoscopy. Rigid urethrocystoscopy was well tolerated by our patients especially in women.

\section{Author's Contribution}

All authors have read and approved the final version of the manuscript.

\section{Conflicts of Interest}

The authors declare no conflicts of interest regarding the publication of this paper.

\section{References}

[1] Martin, M. and Fangerau, H. (2011) Gaining Insight Visualization of the Invisible in Urology: On the History of the Technique and Evidence in Urological Endoscopy. Urologe A, 50, 1311-1138. https://doi.org/10.1007/s00120-011-2612-9

[2] Cicione, A., Cantiello, F. and Damiano, R. (2013) Cystoscopy in Non-Muscle-Invasive Bladder Cancer: When and How (Rigid or Flexible). Urologia, 80, 11-15. https://doi.org/10.5301/RU.2013.10858

[3] Klotz, F. (2003) L'endoscopie dans les pays en voie de développement. Acta Endoscopica, 33, 756-757. https://doi.org/10.1007/BF03002617

[4] Jalloh, M., Niang, L., Andjanga-Rapono, Y.E., Ndoye, M., et al. (2015) Urétrocystoscopie ambulatoire au service d'Urologie/Andrologie de l'Hôpital Général Grand Yoff de Dakar. African Journal of Urology, 22, 115-120.

https://doi.org/10.1016/j.afju.2015.05.008 
[5] Samuel, A.D, Dattatraya, P., Mehrdad, A. and Muta, M. (2016) Urologist Use of Cystoscopy for Patients Presenting with Hematuria in the United States. Urology, 100, 20-26.

[6] Kane, R., Niang, L., Diallo, Y., Jalloh, M., et al. (2014) Advanced Bladder Cancer in Senegal: Epidemiological and Clinical Aspects. Open Journal of Urology, 4, 127-131. https://doi.org/10.4236/oju.2014.411022

[7] Diao, B., Amath, T., Fall, B., Fal,l P.A, Diémé, M.J., Steevy, N., et al. (2008) Les cancers de la vessie au Sénégal: Particularités épidémiologiques, cliniques et histologiques. Progrès en Urologie, 18, 445-448. https://doi.org/10.1016/j.purol.2008.04.016

[8] Vasdev, N., Kumar, A., Veeratterapillay, R. and Thorpe, A.C. (2012) Hematuria Secondary to Benign Prostatic Hyperplasia: Retrospective Analysis of 166 Men Identified in a Single One Stop Hematuria Clinic. Current Urology, 6, 146-149. https://doi.org/10.1159/000343529

[9] Lee, J.W., Doumouchtsis, S.K., Jefery, S. and Fynes, M. (2009) Evaluation of Outpatient Cystoscopy in Urogynaecology. Archives of Gynecology and Obstetrics, 279, Article No. 631. https://doi.org/10.1007/s00404-008-0773-6

[10] Rabischong, B. (2017) Anatomie des systèmes urinaire et pelvien de la femme. In: Deffieux, X., Ed., Incontinence Urinaire Féminine, Elsevier Masson, Paris, 3-12. https://doi.org/10.1016/B978-2-294-75732-7.00001-7

[11] Goldfischer, E.R., Cromie, W.J., Karrison, T.G., Naszkiewicz, L. and Gerber, G.S. (1997) Randomized, Prospective, Double-Blind Study of the Effects on Pain Perception of Lidocaine Jelly Versusplain Lubricant during Outpatient Rigid Cystoscopy. Journal of Urology, 157, 90-94. https://doi.org/10.1016/S0022-5347(01)65292-3

[12] Greenstein, A., Greenstein, I., Senderovich, S. and Mabjeesh, N.J. (2014) Is Diagnostic Cystoscopy Painful? Analysis of 1,320 Consecutive Procedures. International Brazilian Journal of Urology, 40, 533-538. https://doi.org/10.1590/S1677-5538.IBJU.2014.04.13

[13] Seklehner, S., Remzi, M., Fajkovic, H., Saratlija-Novakovic, Z., Skopek, M., Resch, I., et al. (2015) Prospective Multi-Institutional Study Analyzing Pain Perception of Flexible and Rigid Cystoscopy in Men. Urology, 85, 737-741. https://doi.org/10.1016/j.urology.2015.01.007

[14] Seklehner, S.A., Remzi, M., Fajkovic, H., Saratlija-Novakovic, Z. and Skopek, M., Resch, I., et al. (2015) A Multi-Institutional Trial Analyzing Pain Perception of Flexible and Rigid Cystoscopy in Men. European Urology Supplements, 14, e839-e839a. https://doi.org/10.1016/S1569-9056(15)60828-4

[15] Pescheloche, P., Gallon, J., Parier, B., Bessede, T., Irani, J., Verrier, C. and Hammoudi, Y. (2017) Faut-il contrôler la stérilité des urines avant cystoscopie en externe? Progrès en Urologie, 27, 728-729. https://doi.org/10.1016/j.purol.2017.07.107

[16] Karmouni, T., Bensalah, K., Alva, A., Patard, J.J., Lobel, B. and Guillé, F. (2001) Role of Antibiotic Prophylaxis in Ambulatory Cystoscopy. Progrès en Urologie, 11, 1239-1241. 